\title{
E-Metrics and Library Assessment in Action
}

Virginia Kinman, M.A., M.Ln.

Electronic Resources Librarian and Associate Professor

Longwood University, Farmville, VA

Submitted September 29, 2008

Author Posting. (C) Taylor \& Francis Group, LLC, 2009.

This is the author's version of the work as submitted for peer review. It is posted here by permission of Taylor \& Francis for personal use, not for redistribution.

This is a pre-print of an article whose final and definitive form was published in Journal of Electronic Resources Librarianship, Volume 21 Issue 1, January 2009. doi:10.1080/19411260902858318 (http://dx.doi.org/10.1080/19411260902858318) 


\section{E-Metrics and Library Assessment in Action}

\section{ABSTRACT:}

Digital resources play an increasingly important role in academic libraries, which must demonstrate their value to the institution and their impact on student learning outcomes in new and more compelling ways. This study examines five years of vendor-supplied e-resource usage data in conjunction with other library and institution measures. Results are compared to major findings from other researchers, with examples of how e-metrics can be incorporated into a broader assessment of how the library is meeting the needs of its users.

\section{KEYWORDS:}

E-metrics, library assessment, COUNTER, vendor-supplied usage data, federated searching, link resolvers

\section{INTRODUCTION}

The increasingly important role of electronic resources and services in libraries is evident from even a cursory review of the professional literature, the blogosphere and conference presentations. If academic libraries in the web 2.0 world are indeed becoming "collaborators in a multimedia-rich, user-empowered, disintermediated free-for-all where their value will be proven only by demonstrably improving outcomes in learning, teaching, and research” (Wawrzaszek and Wedaman 2008, 2), then academic librarians must demonstrate in new and more compelling ways how electronic resources contribute to the goals of their institutions. This requires moving beyond using e-metrics solely for collection management or budgetary decisions to exploring and validating the relationship between electronic resources and other measures of library and institutional outcomes. COUNTER standards, while not perfect, have developed to a point where trend analysis and benchmarking of e-metrics are both possible and desirable (Taylor-Roe and Spencer 2005; Best 2007; Conyers and Dalton 2007; Whitehead 2007) .

This study evolved from efforts at an academic library in a Master's I institution to track trends in electronic resource usage statistics over time through the use of constant data sets and to find innovative ways to use that data in communicating the value of the library to the administration. The literature review presents recent developments in academic library assessment and e-metrics research relevant to the study. Five years of vendor-supplied e-resource usage data are examined in conjunction with other library and institution measures. COUNTER metrics and ratios are compared to major findings from other researchers and discussed in light of the local setting. E-metrics data are then incorporated into a broader assessment of how the library is meeting the needs of its users by employing an adaption of Edward Tufte's sparklines. Implications for the future and suggestions for additional research are also provided.

\section{LITERATURE REVIEW}

In 1998, the International Coalition of Library Consortia (ICOLC) produced guidelines that sought to provide a "common set" of data elements to be incorporated into both vendorsupplied and locally derived electronic resource usage data. The ICOLC guidelines launched a decade of efforts to define, validate, standardize, and analyze usage statistics for an increasingly complex and integrated universe of electronic resources. The Association of Research Libraries (ARL) took the lead in the U.S. with its E-Metrics Project, started in early 1999 (Miller and Schmidt 2001; ARL 2002; Shim and McClure 2002; ARL 2007) and followed by other studies 
of how ARL libraries deal with e-resource usage data (Beck 2003; Lakos 2007; Martell 2007) as well as the MaxData project (Tenopir 2005; Baker 2006; Tenopir et al. 2007) and related research (Baker and Read 2008). The e-measures project launched in 2003 (Evidence Base 2007) and the National E-Journals Initiative, known as NESLi2 (Conyers 2006; Conyers and Dalton 2007), have guided reporting and analysis of e-resources in academic institutions in the United Kingdom. Several monographs provide an overview of developments related to e-resource usage (Fowler 2004; White and Kamal 2006; Fowler 2007; Matthews 2007). Rous (2004) offers a publisher's perspective of e-metrics. Rowlands (2007) updates Tenopir's (2003) review of research about user behavior and electronic resources.

Project COUNTER (Counting Online Usage of NeTworked Electronic Resources) brought librarians, publishers and vendors together in 2002 to develop detailed standards for reporting and recording online usage data. Release 3 of the COUNTER Code of Practice for Journals and Databases (2008a) was published in August 2008 and addresses issues such as incorporation of SUSHI (Standardized Usage Statistics Harvesting Initiative), consortium reports, separating journal archive packages, and accounting for federated searches. Vendor adoption of the COUNTER standards has grown steadily. The number of COUNTER-compliant vendors has more than doubled since August 2005. Of the 100 vendors compliant with Release 2 as of July 2008 (COUNTER 2008b), 92 provide the JR1 report (successful full-text article requests by journal), 26 provide the DB1 report (total searches and sessions by database), and 41 provide the DB3 report (total searches and sessions by service). Two-thirds of vendors providing JR1 also provide the optional JR3 report (successful item requests and turnaways by journal and page type) and over one-third also provide the JR4 report (total searches by month and service). The ICOLC endorsed the COUNTER standards in March 2003 and again in its revised guidelines (2006).

Although COUNTER has developed and gained acceptance in both the publisher and library worlds, researchers have noted a number of factors that may influence or are not reflected in quantitative e-resource usage data. These include how long a resource has been available (Townley and Murray 1999; Ferguson 2003; Kidd 2005), the path a user takes to get to a full-text article (Duy 2004; Pesch 2004; Coombs 2007), link resolver impact (Lorbeer 2005; Belvadi 2006; Brady, McCord, and Galbraith 2006; McDonald 2007; Yi and Herlihy 2007), federated searching (Blecic, Fiscella, and Wiberly 2007; McDonald 2007), print vs. online usage (King et al. 2003; Brady, McCord, and Galbraith 2006; McDonald 2006; Conyers and Dalton 2007; Cooper 2007), the user's interaction with the resource (Conger 2007), discrepancies in the number of "big deal" titles and titles included in usage data (Conyers and Dalton 2007), the lack of open access usage data (Franklin and Plum 2006), the value of the resource (Shim, Murphy, and Brunning 2004; Medeiros 2007), and vendor interface (Davis and Price 2006). Peters demonstrates this dual-edged aspect of e-metrics when he asserts in the same article that usage statistics "may not move us any closer to a clear understanding of real use of information than did gate counts and circulation statistics" and that they also "represent a huge opportunity to transform the profession. We may be able to systematically learn more about the online information seeking and usage patterns and needs of library patrons than we ever hoped to know about their use of physical libraries" (2002, 44, 46).

Several studies indicate that the most common uses of e-metrics are for collection management and budgetary reasons. Shim and McClure found that almost two-thirds of ARL libraries "used electronic resource statistics to make electronic database subscription decisions" (2002, 228). The top three uses of e-metrics by directors of academic libraries in Connecticut 
were related to purchasing decisions or justifying budgets (Abatelli 2007). In a 2006 survey of 92 Carnegie I and II research institution library directors, the two most cited reasons for analysis of vendor-supplied usage data were subscription decisions (94\%) and justifying expenditures (86 \%) (Baker and Read 2008, 31).

Full-time equivalent (FTE) student population is a common measure for academic institutions. Academic libraries use ratios of various measures per student FTE or combined student and faculty FTE in annual reports (ACRL 2004), though rarely related to non-budgetary aspects of electronic resources. The EQUINOX Project included database sessions per member of the target population as one of fourteen performance indicators for electronic library services (Brophy et al. 2000). Downloads per FTE per year is one of several key performance indicators for e-journals required by the Newcastle University Library (Taylor-Roe 2007). The NESLi2 project included full-text article requests per FTE in its analysis of publisher deals in academic libraries in the United Kingdom (Shepherd 2008a). Blecic, Fiscella, and Wiberly (2001) examined searches, sessions and downloads of discipline-specific resources in relation to the combined FTE faculty and instructional enrollments in the discipline and suggested that per capita use would be a more useful comparative benchmark among academic institutions than raw data.

The literature includes relatively few examples of academic libraries using e-metrics for purposes other than electronic resource collection management or budget decisions. Pesch (2004) and Anderson (2007) suggest that changes in usage data after instruction can serve as a measure of student learning. Usage data trends can inform marketing, promotion and instruction activities (Dubicki 2007). Decreases in interlibrary loan requests may correspond to rising article downloads per year (Taylor-Roe 2007) or increased availability of e-journals (Loy 2007). Usage data can be compared to qualitative data; Newberry (2006) cites one study that found the top $25 \%$ of high use databases coincided with highly valued databases. Brady, McCord, and Galbraith (2006) included gate count in their study of print and electronic journal use over three non-consecutive years but focused primarily on differences related to disciplines and link resolver data. As Anderson asserts, "the biggest challenge in maximizing the utility of e-serial usage data may be simply recognizing new opportunities for using this data” $(2005,22)$.

Academic libraries must look beyond traditional input and output measures to those that will reflect and support the role of the academic library today, such as quality of service, customer satisfaction, and outcomes assessment (Covey 2005; Weiner 2005). For example, the increased emphasis on student learning in higher education forces libraries to incorporate userfocused qualitative performance measures in order to demonstrate their role in student learning outcomes (Dugan and Hernon 2002; Dalton and McNicol 2004). Aligning library assessment with the needs and expectations of the institution's stakeholders is critical (Harer and Cole 2005; White and Blankenship 2007). In 2002 Shim and McClure urged academic libraries to "consider the planning and evaluation of library networked resources as part of larger organizational planning and evaluation activities” (234). Four years later, Duane Webster opened the first Library Assessment Conference by noting that academic libraries are at a "critical juncture" and "must find ways to integrate [their] library assessment efforts with those of the larger institution" (2007, 3).

\section{SETTING}

Longwood University is a state-supported Master's I institution with an FTE student population of over 4,200 and growing graduate and online programs. From FY03-04 to FY07-08, 
overall student FTE increased 6\%, graduate student FTE increased 40\%, fall enrollment increased $11 \%$, unduplicated headcount increased 22\%, and faculty increased 21\%. Online enrollment has more than tripled since the first course offerings in FY04-05.

The Janet D. Greenwood Library has 332,000 volumes and access to 18,000 electronic books, 30,000 full-text electronic journals, and over 150 electronic databases. Access to many of the full-text journals comes from VIVA, the state-funded consortium for public academic institutions in Virginia. With a relatively flat budget over the last ten years, the library has kept up with serials inflation and added new electronic resources and services primarily through reducing book acquisitions and using one-time and year-end funds to prepay known serials expenses.

The implementation of an information commons in fall 2004 resulted in a 25\% increase in gate count, circulation and e-resource usage (Kocevar-Weidinger, Kinman, and McCaslin 2007) and was the first in a series of major changes at the Greenwood Library. In FY04-05, the library website was redesigned, electronic reserves were introduced, and interlibrary loan was automated with ILLiad. In FY05-06, the library added a link resolver and access to RefWorks. In spring 2007, the library implemented a federated search product and conducted its first LibQUAL+ survey. In spring 2008, a different federated search product was launched and promoted in conjunction with converting the library's research guides to the LibGuides system. At the same time, the information commons was expanded and reconfigured with more collaborative learning spaces.

\section{RESEARCH METHODOLOGY}

This study examines five years of vendor-supplied e-resource usage data in conjunction with other library and institution measures. COUNTER-compliant metrics were available for over half of the resources; non-COUNTER data were equated to the closest approximate COUNTER metric. Monthly usage data were entered into a local Microsoft Access database as searches, sessions, and full-text downloads. Data for e-journal collections and publishers providing access to more than one journal were included at the aggregate database level. Monthly data were aggregated by year, defined as August through July to more closely approximate the academic year and allow for comparing data by academic semester as needed. Yearly statistics included in this study are referred to as fiscal year (FY) data.

Approximately 175 electronic resources (abstracting and indexing databases, databases and aggregators with some form of full text, e-journal collections, e-journal publishers offering access to more than one journal, and e-book collections) were available to Greenwood Library users during the five-year study period of FY03-04 to FY07-08. Resources that were available for at least two of the study years constituted the base set of 156 resources. At least one usage metric was available for two or more years for resources in the base set and formed the overall sample set of 118 resources. The distribution of abstracting and indexing (A\&I) resources, fulltext databases, e-journal providers, and e-book collections in the sample set was similar to the base set, with slightly more A\&I databases and slightly fewer e-journal providers. The base set included 83 resources with COUNTER-compliant usage data, 54,000 online journal titles (not de-duped), and 9,000 e-books. The sample set included 72 resources with COUNTER-compliant usage data, 46,000 online journal titles, and 2,000 e-books.

Only two-thirds (104) of the 156 resources in the base set were available in FY03-04. The number of base resources increased approximately 15\% for the next three years as the library added databases and more vendors began providing usage data. Increases from one year to the 
next where all resources available in the given year are counted could be attributed to an assumption that more resources would naturally lead to more searches, sessions or downloads. While this is not an issue when comparing usage data for a single resource across time for purposes of collection management or budgetary decisions, it could mask patterns in longitudinal analysis of a group of resources.

Constant data sets were therefore created for resources with the same usage data available for five, four, three and two years (see Table 1). This allowed the author to compare usage of a controlled set of resources over time. Comparing a constant set of electronic resources over time may also prevent or limit known--and unknown--influences and inconsistencies in usage data from skewing the results. It should be noted that the constant data sets in this study did not account for changes in the number of full-text resources offered by a provider from year to year.

\section{TABLE 1. COUNTER Metrics for Each Constant Data Set}

\begin{tabular}{|r|c|c|c|c|}
\cline { 2 - 5 } \multicolumn{1}{c|}{} & $\begin{array}{c}\text { FY03-04 } \\
\text { to } \\
\text { FY07-08 } \\
\text { (5 years) }\end{array}$ & $\begin{array}{c}\text { FY04-05 } \\
\text { to } \\
\text { FY07-08 } \\
\text { (4 years) }\end{array}$ & $\begin{array}{c}\text { FY05-06 } \\
\text { to } \\
\text { FY07-08 } \\
\text { (3 years) }\end{array}$ & $\begin{array}{c}\text { FY 06-07 } \\
\text { to } \\
\text { FY07-08 } \\
\text { (2 years) }\end{array}$ \\
\hline Searches & 69 & 76 & 89 & 94 \\
\hline Sessions & 28 & 52 & 66 & 76 \\
\hline Downloads & 32 & 38 & 45 & 48 \\
\hline $\begin{array}{r}\text { Downloads } \\
\text { per Session }\end{array}$ & 16 & 20 & 22 & 24 \\
\hline $\begin{array}{r}\text { Searches } \\
\text { per Session }\end{array}$ & 23 & 42 & 54 & 59 \\
\hline
\end{tabular}

NOTE: In Figures 1-5, the constant data sets for 5, 4, 3, and 2 years of data are represented by the corresponding pattern shown above.

Yearly totals were calculated for each data set and for each COUNTER metric or ratio shown in Table 1. In FY03-04, data for only one constant data set was available. In FY04-05, totals were calculated for two constant data sets: the set of resources available for all five years of the study period and the set of resources available for four years of the study period. In FY0506, totals were calculated for three constant data sets, and in FY06-07 and FY07-08, totals were calculated for all four constant data sets (see Appendix 1). Longitudinal trends were then compared across constant data sets.

Selected COUNTER metrics and ratios for the five-year data sets were graphed as a percentage of the highest value in the five-year period and compared to other library and institutional metrics graphed in the same way. These results are discussed in the section on EMetrics and Library Assessment.

\section{RESULTS}

From FY03-04 to FY06-07, the constant data sets increased in a similar stair-step pattern relative to one another for each of the three COUNTER metrics. Searches decreased slightly in FY07-08 for each data set in similar proportion to the previous years (see Figure 1). Database sessions increased in FY07-08 with greater variation across data sets (see Figure 2). The two- 
year data set increased less and the five-year data set increased more relative to the previous year's pattern. In FY07-08, full-text downloads jumped more than three times the average increase for the previous years, with the two-year data set increasing significantly more than the other data sets (see Figure 3).

FIGURE 1. Database Searches by FY

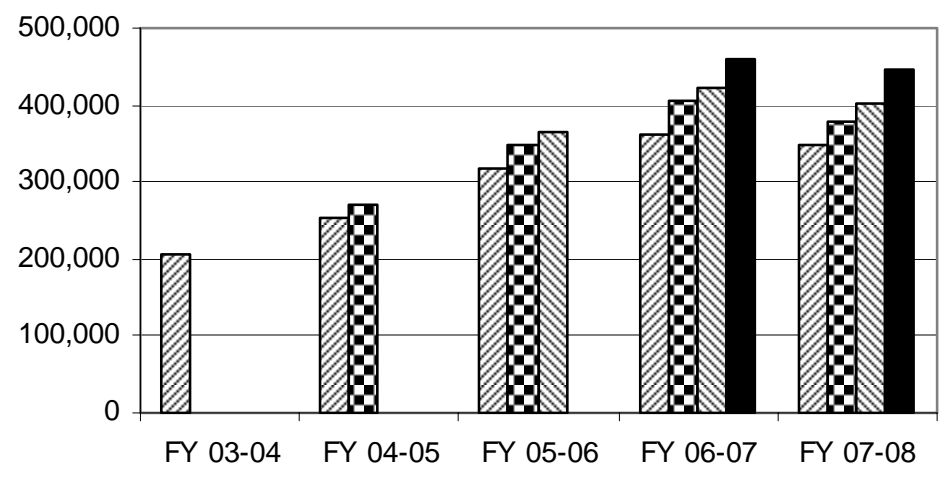

FIGURE 2. Database Sessions by FY

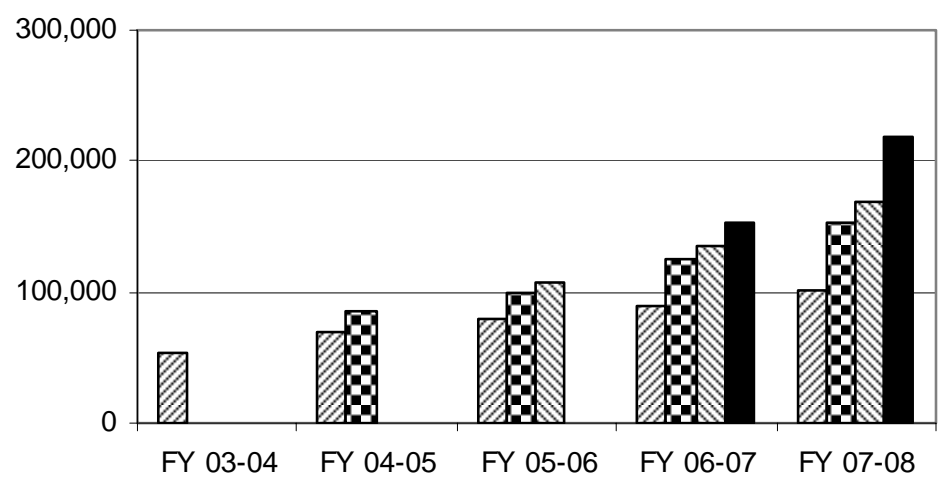

FIGURE 3. Full-Text Downloads by FY

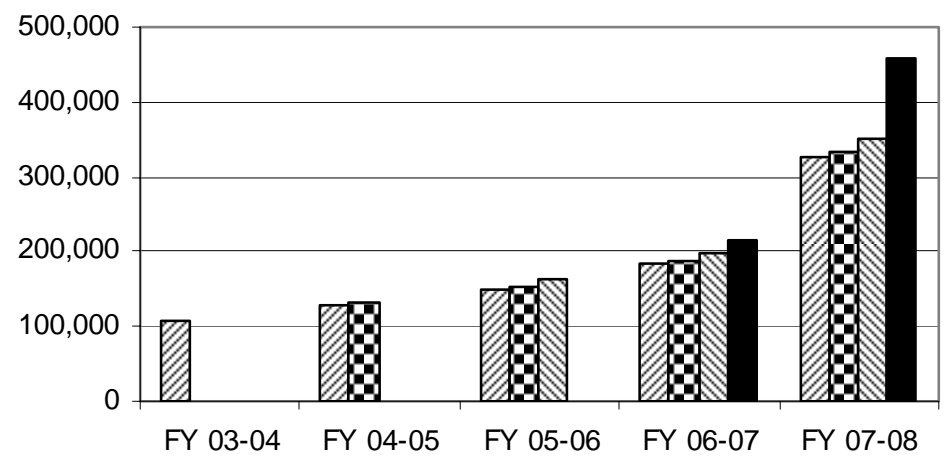

The downloads per session ratio decreased consistently across constant data sets for the first three years (see Figure 4). In FY06-07, the five-year data set had a slightly higher decrease relative to the previous year. In FY07-08 all data sets increased three-fold on average but with 
greater variation. In this case, the three-year and four-year data sets were the outliers, both increasing much more in relation to the other two data sets.

FIGURE 4. Downloads per Session

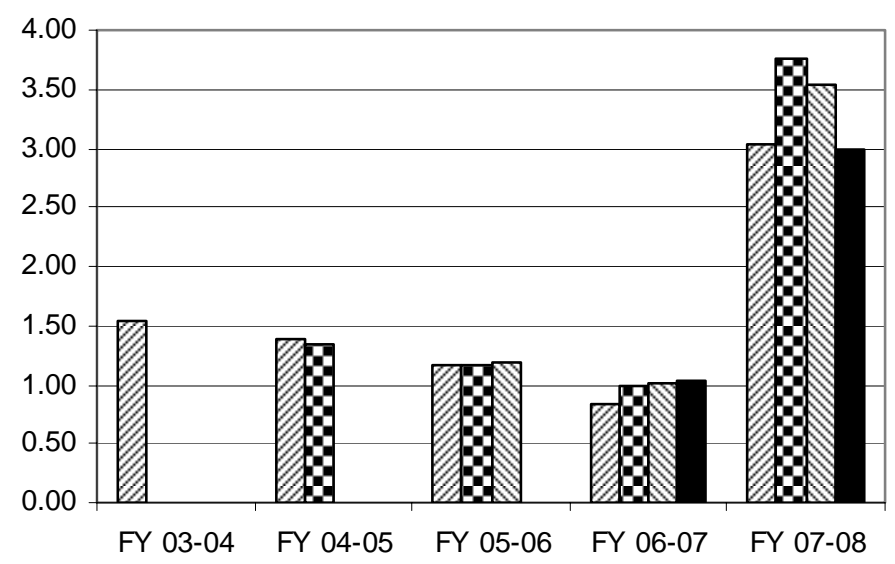

The searches per session ratio was consistent across data sets for each year and for the first three years of the study (see Figure 5). In FY06-07, all data sets decreased by approximately the same percentage, followed by a similar drop in FY07-08.

FIGURE 5. Searches Per Session

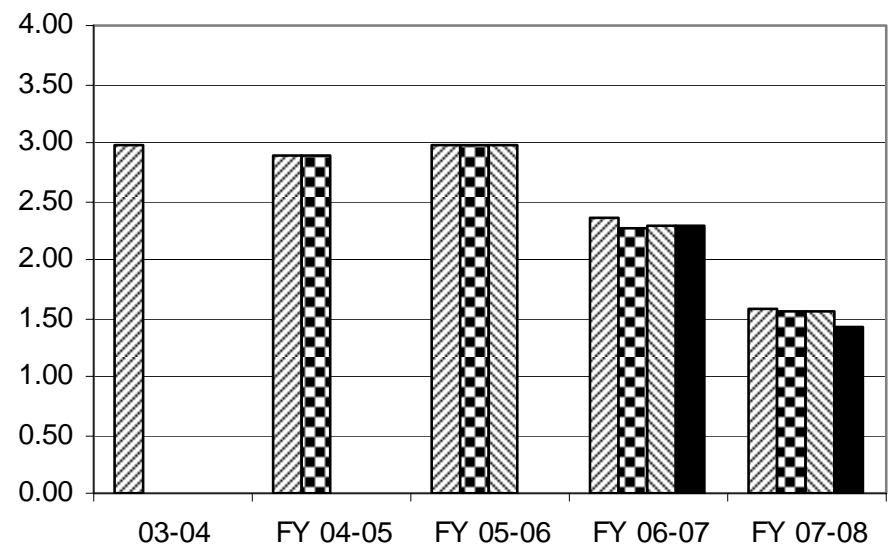

\section{DISCUSSION}

One goal of this study was to determine if the constant data sets confirmed patterns in COUNTER metrics identified by other researchers. The following discussion examines the results in light of the local setting and findings noted in the literature review.

A possible explanation for the unusually high increase in full-text downloads for the twoyear constant data set in FY07-08 (see Figure 3) may be found by looking at the resource level data. Academic OneFile was added to the library’s databases in fall 2006 after the vendor split InfoTrac OneFile into Academic OneFile and General OneFile. All resources on the library’s A 
to $\mathrm{Z}$ and databases by subject pages were sorted alphabetically. Since the library includes all of its major multidisciplinary databases on all subject lists, Academic OneFile became the first database in all lists on the library's web site. Full-text downloads from Academic OneFile increased more than six-fold from FY06-07 to FY07-08 and accounted for over 90\% of the downloads for the three resources in the two-year data set. This, however, does not explain why downloads from Academic OneFile increased so much from the first to second year of availability. Academic OneFile was also a preferred full-text database for the library's link resolver and was included in all categories for both federated search products implemented during those two years.

Searches dropped slightly for all data sets in FY07-08 after four years of steady increase (see Figure 1), while sessions (see Figure 2) and downloads (see Figure 3) increased each year for the entire study period. The searches per session ratio remained consistent for the first three years, ranging from 2.89 to 2.99 across data sets, and then decreased in FY06-07 and again in FY07-08 to an average 1.52 across data sets (see Figure 5 and Appendix 1). This confirms Blecic, Fiscella, and Wiberly's (2001) finding that the searches per session ratio is statistically more stable than either searches or sessions alone if no major changes occur in services or resources. In a later study, the same authors found that the search per session ratio tended to decrease and move toward 1.0 over the course of three years for resources included in federated searching (Blecic, Fiscella, and Wiberly 2007). The Greenwood Library's first federated search product was introduced in FY06-07, followed by another in FY07-08 that was promoted more aggressively. A similar downward trend in the search per session ratio occurred during the last two years of the study period when the federated search products were introduced (see Figure 5). While not within the scope of this paper, an initial review of resources with four years of searches per session data reveals that the search per session ratio of the federated resources dropped an average of 23\% from FY04-05 to FY07-08 and rose an average of 17\% for the nonfederated resources.

Full-text downloads increased 50\% more in FY07-08 for all data sets than in earlier years (see Figure 3). Downloads per session increased sharply and unevenly across data sets in FY0708 after four years of much lower gradual decreases (see Figure 4). The Greenwood Library implemented a link resolver in FY05-06. By FY07-08 it had been configured for one-click to article capability and was more familiar to users. Full-text downloads for non-priority resources in the preferred display order configured in the link resolver decreased in the first link resolver year while priority resources accounted for most of the increase in full-text downloads for both years (Kinman 2008). McDonald (2007) found a statistically significant increase in online journal article downloads after a link resolver was launched. Townley and Murray's (1999) oftcited finding that it takes 12 to 18 months for a resource to reach its full use, if applied to services, may partly explain the sharp increase in the download per session ratio.

\section{E-METRICS AND LIBRARY ASSESSMENT}

All libraries_-academic, public, special, school—rely on their user communities for the support and funding that allows them to serve those users. Digital resources and services make up an increasingly greater proportion of what libraries offer to their users, and in some cases threaten to eclipse or replace the traditional library. Incorporating e-metrics more fully into other quantitative library measures will allow librarians to identify trends and raise questions about the interplay between various services and collections, questions that can then be further explored 
through qualitative assessments such as focus groups, surveys, and usability testing. It must also be a critical component of how libraries communicate their worth to their stakeholders.

Sparklines are data-intense graphics created by Edward Tufte (2004) to track changes over time and show overall trends as well as local detail in a simple, uncluttered design. Others have adapted the concept and developed software and plug-ins to incorporate sparklines into desktop publishing programs. Sparklines display trends in quantitative data for a single variable over time by graphing each data point as a percentage of the highest value, creating a visual that communicates more information more quickly than a table of numerical data.

The sparklines concept can be adapted to illustrate potential relationships between various library metrics (Kinman 2008). A different color or pattern is used for each year so that one can see at a glance how the various metrics compare to one another for a given year or as a trend. Each gridline represents a $25 \%$ difference from the highest value for a given metric. Since change relative to the highest value is the common derivative for each metric, it is not necessary to account for differences in scale. However, numerical data may be provided to supplement the graphics.

The graphs in Figure 6 place selected e-resource usage data within the context of other library measures and institutional growth over the five-year study period. The five-year constant data sets are used for the e-metrics. FTE ratios are calculated for sessions and downloads to provide a more meaningful measure in relation to the institution (Blecic, Fiscella, and Wiberly 2001) and because sessions per FTE and downloads per FTE are key indicators in academic libraries in the United Kingdom (Brophy et al. 2000; Taylor-Roe 2007; Shepherd 2008a). The searches per session ratio is used because of its demonstrated stability over time (Blecic, Fiscella, and Wiberly 2007). Appendix 2 provides the numerical data for the graphs. Discussion of how these graphs may be used to raise questions and identify trends, both for internal library assessment and communication with institutional administrators, follows. 
FIGURE 6. Five-Year Trends, FY03-04 to FY07-08
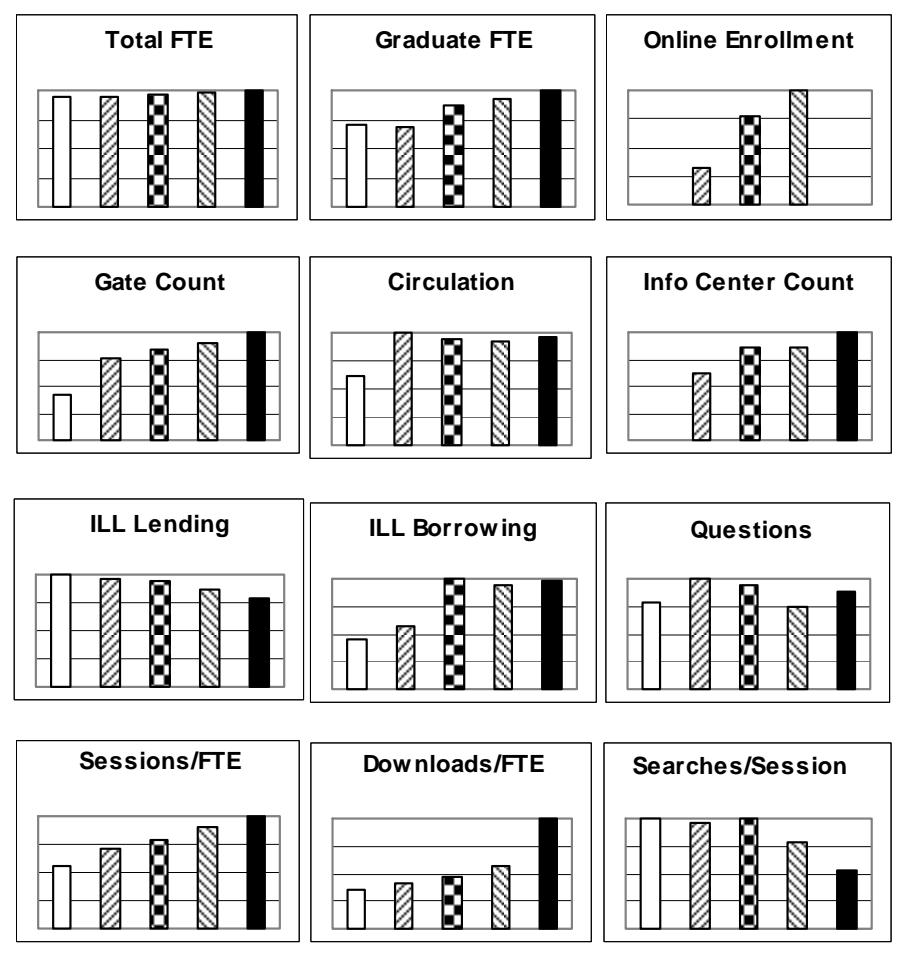

FY03-04 שFY04-05 @FY05-06 \& FY06-07 —FY07-08

The increase in the use of Greenwood Library services and resources over the five years from FY03-04 to FY07-08 exceeds the much smaller increments in FTE over the same period. The sharp increases in gate count and circulation in FY04-05 coincide with the launch of the library’s information commons in fall 2004 (Kocevar-Weidinger, Kinman, and McCaslin 2007). The gate count and information center count continued to increase, as did two measures of usage of electronic resources (downloads per FTE and sessions per FTE), indicating that use of both the physical library and the virtual library is steadily rising. Use of the physical space is confirmed in the 2007 LibQUAL+ finding that $77 \%$ of undergraduates use the library building at least daily or weekly.

The 25\% decrease in questions recorded at the reference and information center desk from FY04-05 to FY06-07 does not follow the same pattern. More students are coming into the information commons area and using the library's electronic resources, but they are asking fewer questions. Is the increase in questions in FY07-08 related to the online chat reference service that is perceived to be very popular with students? Are there fewer reference questions (as a subset of total questions shown in the graph) because the link resolver makes it easier and more seamless to move from citations to full text, or because users are not comfortable asking for help? LibQUAL + results indicate a high level of satisfaction with how the library teaches users to locate, evaluate and use information. What will the institution-wide information literacy assessment program being developed reveal about how well students are applying that selfascribed knowledge? 
Graduate and online enrollment have risen over the past three years. Many of the graduate students are working adults who do not live near the university, and both of these groups rely heavily on electronic resources and services. How much of the increase in use of electronic resources and interlibrary loan, which includes document delivery for distance education students, can be attributed to graduate and online students? Are the needs of this group being met?

The addition of electronic search and discovery tools such as the link resolver, federated search, and ILLiad has cut into the library's relatively flat budget over the past five years. Are these tools leading to increased use of the electronic resources which constitute an increasingly higher percentage of the library's acquisitions expenditures? Interlibrary loan requests, sessions per FTE and full-text downloads per FTE were close to or more than 50\% higher in FY07-08 than in FY03-04, and the searches per session ratio is moving toward 1.0 as expected with the implementation of federated searching (Blecic, Fiscella, and Wiberly 2007). Closer examination of link resolver usage and database-level data may provide additional insights.

Circulation has maintained the increase after FY03-04 when the information commons was created. The library is purchasing fewer than half the number of monographs from five years ago. A closer look at circulation by item type reveals that book circulation increased over $50 \%$ in FY04-05 and despite slight decreases in subsequent years showed a healthy $42 \%$ increase from FY03-04 to FY07-08. Circulation of audiovisual materials, popular with students in this smalltown, residential campus, increased more but follows a similar pattern after the initial jump in FY04-05. Accesses of electronic reserves, which include persistent links to online journal articles where permitted by license terms, have increased 60\% since being implemented in FY05-06.

The Greenwood Library has long been and continues to be a net lender for interlibrary loans. However, that gap is narrowing. Lending is gradually decreasing and borrowing has maintained the 50\% increase experienced in FY05-06 when a new link resolver coupled with ILLiad provided an easy way to place interlibrary loan requests online. Full-text downloads per FTE rose steadily for four years and then jumped almost 50\% in FY07-08. This would appear to contradict Taylor-Roe's (2007) finding that decreases in interlibrary loan requests may correspond to rising article downloads per year. What questions need to be asked in this case?

The preceding discussion illustrates how comparative sparkline-type graphs can help librarians see connections between services and raise questions for further assessment. These graphs, combined with actual data if desired, can provide administrators with a fuller picture of library services and resources through a simple, visual representation of trends. While the data does not conclusively prove the value of the library to the institution, the graphs provide a powerful visual to support the library in its requests for funding.

\section{CONCLUSION AND IMPLICATIONS FOR THE FUTURE}

As with any statistics, the choice and representation of data can hide or overemphasize aspects of the truth. Usage data is imperfect and cannot tell us everything we want to know about how users interact with electronic resources. However, we cannot afford to wait until we have "almost perfect" data to make e-metrics a more integral part of overall library assessment. We must, as Covey urges, "settle for good enough data to get the job done” (2005, 84).

The constant data sets used in this study were time-consuming to create and maintain at the database level in a medium-sized library. Additional research is needed to determine the validity of constant data sets. Are e-resource usage metrics and ratios that use constant data sets for longitudinal analysis statistically more reliable than metrics and ratios that use actual counts 
for all resources available in a given year? If so, is this approach scalable to larger libraries, and would it help address "the true difficulty [which] lies in integrating reports across years," especially for journals (Henle and Cochenour 2007, 17)?

Progress is being made with standards and protocols for recording and managing electronic resource usage data. Release 3 of the COUNTER code of practice addresses, among other things, separate journal archives and federated searching (2008a). The COUNTER standards offer great promise to smaller libraries for whom vendor-supplied data is often the only viable source of electronic resource usage statistics. Vendors of electronic resource management systems and usage data services should work with librarians to incorporate mechanisms to make it easier to extract meaningful data. For example, the ability to track in one place how and when each electronic resource changed in relation to federating searching, priority in link resolver results, position and relative importance on the library website, number of e-journals or e-books in a collection, and availability of COUNTER data would have made the data analysis in this study less tedious. As Blecic, Fiscella, and Wiberly note, "the potential for different innovations to interact increases the complexity of interpretation of use statistics" and necessitates keeping careful records of innovations $(2007,40)$ as well as other activities such as marketing and instruction that could have an impact on e-resource usage.

At the same time, librarians must continue to study the relationships and interactions of electronic resources and services to determine what conclusions are valid. Just as Weiner (2005) explored the relationship between academic library services (reference transactions, bibliographic instruction sessions, and participants in group presentations) and FTE, researchers must determine what, if any, electronic resource and FTE ratios are reliable usage indicators. Coming to a consensus "as to what constitutes acceptable or adequate amounts of usage" must be related to and accompanied by benchmarks and data for peer institutions with similar collections (Best 2007, 200).

The demand for accountability in higher education today challenges libraries to demonstrate their impact on student learning through both qualitative and quantitative assessment. Electronic resources are an integral part of a 2.0 world where "investment in digital resources, or in access to information resources that are not housed or hosted locally, will be the primary means of providing information to an academic community" (Wawrzaszek and Wedaman 2008, 5). E-metrics will continue to play an important role in collection management and budgetary decisions. However, e-metrics must also be increasingly incorporated into overall library assessment measurements that demonstrate how the library contributes to institutional goals. Academic librarians who manage electronic resources and services must continue to ask questions, look beyond e-metrics to a broader assessment picture, and share how they are using e-metrics in their institutions. 


\section{REFERENCES}

Abatelli, Carol. 2007. E-resource management in Connecticut academic libraries: 2005 CCALD survey results. In Usage statistics of e-serials, ed. David C. Fowler, 79-109. Binghamton: Haworth Information Press.

Anderson, Elise. 2007. The next steps in developing usage statistics for e-serials. In Usage statistics of e-serials, ed. David C. Fowler, 245-260. Binghamton: Haworth Information Press.

- 2005. Maximizing the value of usage data. Against the Grain 17 (5): 20-2.

Association of College and Research Libraries (ACRL). 2004. "Standards for Libraries in Higher Education.” American Library Association. http://www.ala.org/ala/acrl/acrlstandards/standardslibraries.cfm.

Association of Research Libraries (ARL). 2007. "E-Metrics: Measures for Electronic Resources.” Association of Research Libraries. http://www.arl.org/stats/initiatives/emetrics/index.shtml.

_. 2002. "Measures for Electronic Resources (E-Metrics): Complete Set.” Washington, DC: Association of Research Libraries. http://www.arl.org/bm doc/e-metrics.pdf.zip.

Baker, Gayle. 2006. Vendor-supplied usage data: Challenges and opportunities. Paper presented at the Electronic Resources \& Libraries Conference, March 23-25, in Atlanta, GA. http://hdl.handle.net/1853/10403.

Baker, Gayle, and Eleanor J. Read. 2008. Vendor-supplied usage data for electronic resources: A survey of academic libraries. Learned Publishing 21 (1): 48-57. doi:10.1087/095315108X247276

Beck, Susan J. 2003. Making informed decisions: The implications of assessment. Paper presented at the11th ACRL National Conference: Learning to Make a Difference, April 1013, in Charlotte, NC. http://www.ala/ala/acrl/acrlevents/beck.PDF.

Belvadi, Melissa. 2006. Usage statistics for serials decision-making. Paper presented at the Electronic Resources \& Libraries Conference, March 23-25, in Atlanta, GA. http://hdl.handle.net/1853/10406.

Best, Rickey. 2007. Lies, damn lies and usage statistics: What's a librarian to do? In Usage statistics of e-serials, ed. David C. Fowler, 199-214. Binghamton: Haworth Information Press.

Blecic, Deborah D., Joan B. Fiscella, and Stephen E. Wiberley Jr. 2007. Measurement of use of electronic resources: Advances in use statistics and innovations in resource functionality. College \& Research Libraries 68 (1): 26-44.

- 2001. The measurement of use of web-based information resources: An early look at vendor-supplied data. College \& Research Libraries 62 (5): 434-53.

Brady, Eileen E., Sarah K. McCord, and Betty Galbraith. 2006. Print versus electronic journal use in three Sci/Tech disciplines: The cultural shift in process. College \& Research Libraries 67 (4): 354-63.

Brophy, Peter, Zoe Clarke, Monica Brinkley, Sebastian Mundt, and Roswita Poll. 2000. "Library Performance Measurement and Quality Management System: Performance Indicators for Electronic Library Services.” EQUINOX. http://equinox.dcu.ie/reports/pilist.html.

Conger, Joan E. 2007. Usage statistics in context: Develop effective assessment practices through collaboration. In Usage statistics of e-serials, ed. David C. Fowler, 261-273. Binghamton: Haworth Information Press. 
Conyers, Angela. 2006. Building on sand? Using statistics measures to assess the impact of electronic services. Performance Measurement and Metrics 7 (1): 37-44. doi:10.1108/14678040610654846

Conyers, Angela, and Peter Dalton. 2007. Electronic resource measurement: Linking research to practice. The Library Quarterly 77 (4): 463-70. doi:10.1086/521087

Coombs, Karen A. 2007. From what to why: Electronic usage data in collection development and user behavior. Paper presented at Understanding the Data Around Us: Gathering and Analyzing Usage Data, NISO Usage Data Forum, November 1-2, in Dallas, TX. http://niso.kavi.com/news/events/niso/past/usage07/usage07coombs.pdf.

Cooper, Mindy M. 2007. The importance of gathering print and electronic journal use data: Getting a clear picture. Serials Review 33 (3): 172-4. doi:10.1016/j.serrev.2007.06.001

COUNTER: Counting Online Usage of NeTworked Electronic Resources . 2008a. "The COUNTER Code of Practice, Journals and Databases: Release 3.” COUNTER. http://www.projectcounter.org/r3/Release3D9.pdf.

_. 2008b. "Register of vendors.” http://projectcounter.org/compliantvendors.html.

Covey, Denise Troll. 2005. Using data to persuade: State your case and prove it. Library Administration \& Management 19 (2): 82-9.

Dalton, Pete, and Sarah McNicol. 2004. Balancing the books: Emphasizing the importance of qualitative evaluation for understanding electronic information services. The Library Quarterly 74 (4): 455-68. doi:10.1086/427415

Davis, Philip M., and Jason S. Price. 2006. eJournal interface can influence usage statistics: Implications for libraries, publishers, and project COUNTER. Journal of the American Society for Information Science and Technology 57 (9): 1243-8. doi:10.1002/asi.20405

Dubicki, Eleonora. 2007. Statistics drive marketing efforts. In Usage statistics of e-serials, ed. David C. Fowler, 215-231. Binghamton: Haworth Information Press.

Dugan, Robert E., and Peter Hernon. 2002. Outcomes assessment: Not synonymous with inputs and outputs. The Journal of Academic Librarianship 28 (6): 376-80. doi:10.1016/S00991333(02)00339-7

Duy, Joanna. 2004. Usage data: Issues and challenges for electronic resource collection management. In E-serials collection management: Transitions, trends, and technicalities, ed. David C. Fowler, 111-138. New York: Haworth Information Press.

Evidence Base: Research \& Evaluation Services, Birmingham City University Library Services, University of Central England. 2007. "Libraries: Outcomes and Measures.” Birmingham City University. http://www.ebase.bcu.ac.uk/emeasures/index.htm.

Ferguson, Anthony. 2003. Back talk--use statistics: Are they worth it? Against the Grain 14 (6): 93-4. http://www.against-the-grain.com/TOCFiles/Backtalk14_6.pdf.

Fowler, David C., ed. 2007. Usage statistics of e-serials. Binghamton: Haworth Information Press.

— ed. 2004. E-serials collection management: Transitions, trends, and technicalities. New York: Haworth Information Press.

Franklin, Brinley, and Terry Plum. 2006. Successful web survey methodologies for measuring the impact of networked electronic services (MINES for libraries). IFLA Journal 32 (1): 2840. doi:10.1177/0340035206063885

Harer, John B., and Bryan R. Cole. 2005. The importance of the stakeholder in performance measurement: Critical processes and performance measures for assessing and improving academic library services and programs. College \& Research Libraries 66 (2): 149-70. 
Henle, Alea, and Donnice Cochenour. 2007. Practical considerations in the standardization and dissemination of usage statistics. In Usage statistics of e-serials, ed. David C. Fowler, 5-23. Binghamton: Haworth Information Press.

International Coalition of Library Consortia (ICOLC). 2006. "Revised Guidelines for Statistical Measures of Usage of Web-Based Information Resources.” ICOLC. http://www.library.yale.edu/consortia/webstats06.html.

—. 1998. "Guidelines for Statistical Measures of Usage of Web-Based Indexed, Abstracted, and Full Text Resources.” ICOLC. http://www.library.yale.edu/consortia/webstats.html.

Kidd, Tony. 2005. Usage statistics and how we're using them: The example of Glasgow University. In What counts and what doesn't: An insider's guide to usage reports, ed. Martha Borghuis, 3. San Diego, CA: Elsevier.

King, Donald W., Peter B. Boyce, Carol Hansen Montgomery, and Carol Tenopir. 2003. Library economic metrics: Examples of the comparison of electronic and print journal collections and collection services. Library Trends 51 (3): 376-400.

http://vnweb.hwwilsonweb.com/hww/jumpstart.jhtml?recid=0bc05f7a67b1790eccbd4fe8b5 542cfaf1ba69dddfd04b93bb6543f26ffd1620e1fcde8eb8be0116\&fmt=P.

Kinman, Virginia. 2008. Putting the trees back in the forest: E-resource usage statistics and library assessment. Paper presented at the Electronic Resources \& Libraries Conference, March 18-21, in Atlanta, GA. http://hdl.handle.net/1853/20665.

Kocevar-Weidinger, Elizabeth, Virginia Kinman, and Sharon McCaslin. 2007. Case study: The inch and the mile: Luck, opportunity, and planning innovative learning spaces. Library Administration \& Management 21 (1): 29-34.

Lakos, Amos. 2007. Evidence-based library management: The leadership challenge. portal: Libraries and the Academy 7 (4): 431-50. doi:10.1353/pla.2007.0049

Lorbeer, Elizabeth R. 2005. COUNTER data: Expanding horizons for librarians and users. In What counts and what doesn't: An insider's guide to usage reports, ed. Martha Borghuis, 6. San Diego, CA: Elsevier.

Loy, John. 2007. Electronic journals appear to reduce interlibrary lending in academic libraries. Evidence Based Library and Information Practice 2 (1): 140-3. http://ejournals.library.ualberta.ca/index.php/EBLIP/article/view/147/226.

Martell, Charles. 2007. The elusive user: Changing use patterns in academic libraries 1995 to 2004. College \& Research Libraries 68 (5): 435-44.

Matthews, Joseph R. 2007. The evaluation and measurement of library services. Westport, CT: Libraries Unlimited.

McDonald, John. 2007. Usage statistics and information behaviors: Understanding user behavior with quantitative indicators. Paper presented at Understanding the Data Around Us: Gathering and Analyzing Usage Data, NISO Usage Data Forum, November 1-2, in Dallas, TX. http://niso.kavi.com/news/events/niso/past/usage07/usage07mcdonald.pdf.

McDonald, John D. 2006. Understanding online journal usage: A statistical analysis of citation and use. Journal of the American Society for Information Science and Technology 57 (13): 1-13.

Medeiros, Norm. 2007. Uses of necessity or uses of convenience? What usage statistics reveal and conceal about electronic serials. In Usage statistics of e-serials., ed. David C. Fowler, 233-243. Binghamton: Haworth Information Press.

Miller, Rush, and Sherrie Schmidt. 2001. E-metrics: Measures for electronic resources. Paper presented at the 4th Northumbria International Conference on Performance Measurement in 
Libraries and Information Services, August 12-16, in Pittsburgh, PA. http://www.arl.org/stats/newmeas/emetrics/miller-schmidt.pdf.

Newberry, Michele. 2006. Gathering statistics or .... Paper presented at the Online Usage Statistics: Current Status and Future Directions Forum, NFAIS Committee on Best Practices and Usage Statistics, October 27, in Philadelphia, PA. http://www.nfais.org/Newberry_Usage.ppt.

Pesch, Oliver. 2004. Usage statistics: Taking e-metrics to the next level. The Serials Librarian 46 (1/2): 143-54.

Peters, Thomas A. 2002. What's the use? The value of e-resource usage statistics. New Library World 103 (1/2): 39-47. doi:10.1108/03074800210415050

Rous, Bernard, ed. 2004. Online usage: A publisher's guide. New York: Professional and Scholarly Publishing Division, Association of American Publishers.

Rowlands, Ian. 2007. Electronic journals and user behavior: A review of recent research. Library \& Information Science Research 29 (3): 369-96. doi:10.1016/j.lisr.2007.03.005

Shim, Wonsik, and Charles R. McClure. 2002. Data needs and use of electronic resources and services at academic research libraries. portal: Libraries and the Academy 2 (2): 217-36. doi:10.1353/pla.2002.0043

Shim, Wonsik, Kurt Murphy, and Dennis Brunning. 2004. Usage statistics for electronic services and resources: A library perspective. In Online usage: A publisher's guide, ed. Bernard Rous, 34-46. New York: Professional and Scholarly Publishing Division, Association of American Publishers.

Taylor-Roe, Jill. 2007. Usage statistics in an academic library: Some practical applications. Paper presented at Developing Your Library Collections: An International Perspective, in X'ian, China. http://www.oxfordjournals.org/china/news/jilltaylor_usage_statistics.ppt.

Taylor-Roe, Jill, and Cliff Spencer. 2005. A librarian's view of usage metrics: Through a glass darkly? Serials 18 (2): 124-31. doi:10.1629/18124

Tenopir, Carol. 2005. "Maximizing Library Investments in Digital Collections Through Better Data Gathering and Analysis (MaxData).” eds. Donald W. King, Gayle Baker, Eleanor Read and David Nicholas. http://web.utk.edu/ tenopir/maxdata/.

- 2003. Use and users of electronic library resources: An overview and analysis of recent research studies. Washington, DC: Council on Library and Information Resources. http://www.clir.org/pubs/reports/pub120/pub120.pdf.

Tenopir, Carol, Gayle Baker, Eleanor J. Read, Maribeth Manoff, Kitty McClanahan, David Nicholas, and Donald W. King. 2007. MaxData: A project to help librarians maximize ejournal usage data. In Usage statistics of e-serials, ed. David Fowler, 55-77. Binghamton: Haworth Press.

Townley, Charles T., and Leigh Murray. 1999. Use-based criteria for selecting and retaining electronic information: A case study. Information Technology and Libraries 18 (1): 32-9.

Tufte, Edward. 2004. "Sparklines: Theory and Practice.” http://www.edwardtufte.com/bboard/qand-a-fetch-msg?msg_id=0001OR\&topic_id=1.

Wawrzaszek, Susan V., and David G. Wedaman. 2008. The academic library in a 2.0 world. Research Bulletin, no. 19, EDUCAUSE Center for Applied Research. http://www.educause.edu/ecar.

Webster, Duane E. 2007. Library assessment: Demonstrating value-added in a time of constrained resources and unique opportunities. In Proceedings of the Library Assessment Conference: Building Effective, Sustainable, Practical Assessment, September 25-27, 2006, 
Charlottesville, VA, ed. Francine DeFranco, Steve Hiller, Lisa Janicke Hinchliffe, Kristina Justh, Martha Kyrillidou, Jim Self, and Joan Stein, 1-4. Washington, DC: Association of Research Libraries.

Weiner, Sharon A. 2005. Library quality and impact: Is there a relationship between new measures and traditional measures? The Journal of Academic Librarianship 31 (5): 432-7. doi:10.1016/j.acalib.2005.05.004

White, Andrew C., and Eric Djira Kamal. 2006. E-metrics for library and information professionals: How to use data for managing and evaluating electronic resource collections. New York: Neal-Schuman Publishers.

White, Larry Nash, and Emily F. Blankenship. 2007. Aligning the assessment process in academic libraries for improved demonstration and reporting of organizational performance. College \& Undergraduate Libraries 14 (3): 107-19.

Whitehead, Derek. 2007. Why have statistics? ... And what? Paper presented at the CEIRC Forum on Usage Statistics for E-Resources, in Sydney, Australia. http://www.caul.edu.au/datasets/usagestatistics2007whitehead.pdf.

Yi, Hua, and Catherine Herlihy. 2007. Assessment of the impact of an open-URL link resolver. New Library World 108 (7/8): 317-31. doi:10.1108/03074800710763617 
APPENDIX 1. COUNTER Metrics and Ratios by FY and Constant Data Set

\begin{tabular}{rrrrrr}
\hline Searches & FY 03-04 & FY 04-05 & FY 05-06 & FY 06-07 & FY 07-08 \\
\hline 69 resources & 206,694 & 252,705 & 318,076 & 361,278 & 346,708 \\
76 resources & & 270,196 & 347,531 & 403,736 & 377,978 \\
89 resources & & & 363,673 & 423,261 & 401,981 \\
94 resources & & & & 460,714 & 447,015 \\
\hline & & & & & \\
Sessions & FY 03-04 & FY 04-05 & FY 05-06 & FY 06-07 & FY 07-08 \\
\hline 28 resources & 54,324 & 69,316 & 78,552 & 90,099 & 101,450 \\
52 resources & & 85,173 & 100,318 & 124,515 & 152,681 \\
66 resources & & & 107,545 & 135,190 & 167,964 \\
76 resources & & & & 152,288 & 218,217 \\
\hline & & & & & \\
Downloads & FY 03-04 & FY 04-05 & FY 05-06 & FY 06-07 & FY 07-08 \\
\hline 32 resources & 109,324 & 129,756 & 147,630 & 183,192 & 327,032 \\
38 resources & & 132,769 & 153,995 & 187,925 & 334,619 \\
45 resources & & & 162,133 & 198,145 & 351,919 \\
48 resources & & & & 215,641 & 459,015 \\
\hline Downloads & & & & & \\
per Session & FY 03-04 & FY 04-05 & FY 05-06 & FY 06-07 & FY 07-08 \\
\hline 16 resources & 1.54 & 1.39 & 1.16 & 0.83 & 3.03 \\
20 resources & & 1.35 & 1.17 & 0.99 & 3.77 \\
22 resources & & & 1.18 & 1.01 & 3.54 \\
24 resources & & & & 1.02 & 2.98 \\
\hline Searches & & & & & \\
per Session & FY 03-04 & FY 04-05 & FY 05-06 & FY 06-07 & FY 07-08 \\
\hline 23 resources & 2.98 & 2.89 & 2.98 & 2.36 & 1.59 \\
42 resources & & 2.89 & 2.97 & 2.28 & 1.55 \\
54 resources & & & 2.99 & 2.28 & 1.56 \\
59 resources & & & & 2.28 & 1.41 \\
\hline & & & & &
\end{tabular}


APPENDIX 2. Five-Year Trends, FY03-04 to FY07-08

\begin{tabular}{rrrrrr}
\hline & FY 03-04 & FY 04-05 & FY 05-06 & FY 06-07 & FY 07-08 \\
\hline Total FTE & 3,995 & 4,015 & 4,099 & 4,165 & 4,224 \\
\hline $\begin{array}{r}\text { Graduate FTE } \\
\text { Online }\end{array}$ & 300 & 288 & 363 & 386 & 421 \\
Enrollment & & 522 & 1,279 & 1,654 & N/A \\
\hline & & & & & \\
\hline Grate Count & 162,747 & FY 04-05 & FY 05-06 & FY 06-07 & FY 07-08 \\
\hline Circulation & 172,825 & 289,788 & 316,939 & 344,572 & 380,684 \\
\hline $\begin{array}{r}\text { Information } \\
\text { Center Count }\end{array}$ & & 48,453 & 67,376 & 261,120 & 269,793 \\
\hline & & & 67,800 & 78,283 \\
\hline ILL Lending & $5,184-04$ & FY 04-05 & FY 05-06 & FY 06-07 & FY 07-08 \\
\hline ILL Borrowing & 1,680 & 2,958 & 4,890 & 4,456 & 4,090 \\
\hline Questions & 10,284 & 13,169 & 12,428 & 3,437 & 3,579 \\
\hline & FY 03-04 & FY 04-05 & FY 05-06 & FY 06-07 & FY 07-08 \\
\hline $\begin{array}{r}\text { Sessions } \\
\text { per FTE }\end{array}$ & 14 & 17 & 19 & 22 & 24 \\
\hline $\begin{array}{r}\text { Downloads } \\
\text { per FTE }\end{array}$ & 27 & 32 & 36 & 44 & 77 \\
\hline $\begin{array}{r}\text { Searches } \\
\text { per Session }\end{array}$ & 3.0 & 2.9 & 3.0 & 2.4 & 1.6 \\
\hline
\end{tabular}

